\title{
Gender difference and genetic variance in lipoprotein receptor-related protein 1 is associated with mortality
}

\author{
URBAN ALEHAGEN $^{1}$ and DICK WÅGSÄTER ${ }^{2}$ \\ ${ }^{1}$ Division of Cardiovascular Medicine, Faculty of Medicine and Health Sciences, Linköping University, \\ SE-581 85 Linköping; ${ }^{2}$ Department of Medical Cell Biology, Uppsala University, SE-751 23 Uppsala, Sweden
}

Received December 19, 2018; Accepted May 2, 2019

DOI: $10.3892 /$ br.2019.1217

\begin{abstract}
Cardiovascular diseases are an important health resource problem and studies have shown a genetic association between single nucleotide polymorphisms (SNPs) and cardiovascular diseases. According to the literature, lipoprotein receptor-related protein 1 (LRP1) is associated with coronary artery disease. The aim of the present study was to evaluate a possible association between different genotypes of LRP1 and all-cause and cardiovascular mortality from a gender perspective. In the present study, 489 elderly community-living people were invited to participate. Clinical examination, echocardiography and blood sampling including SNP analyses of LRP1 (rs1466535) were performed, including the T/T, C/T and C/C genotypes, and the participants were followed for 6.7 years. During the follow-up period, 116 (24\%) all-cause and 75 (15\%) cardiovascular deaths were registered. In the female population, the LRP1 of the T/T or C/T genotype exhibited a 5.6-fold increased risk of cardiovascular mortality and a 2.8-fold increased risk of all-cause mortality compared with the $\mathrm{C} / \mathrm{C}$ genotype. No such genotype differences could be seen in the male population. Gender differences could be seen regarding the risk of mortality in the different genotypes. Females with the LRP1 T/T or C/T genotypes exhibited a significantly increased risk of both all-cause and cardiovascular mortality compared with the $\mathrm{C} / \mathrm{C}$ genotypes. Therefore, more individualized cardiovascular prevention and treatment should be prioritized. However, since this was a small study, the observations should only be regarded as hypothesis-generating.
\end{abstract}

Correspondence to: Professor Urban Alehagen, Division of Cardiovascular Medicine, Faculty of Medicine and Health Sciences, Linköping University, SE-581 85 Linköping, Sweden

E-mail: urban.alehagen@liu.se

Abbreviations: CI, confidence interval; CV, cardiovascular; ECG, electrocardiogram; EF, ejection fraction; HR, hazard ratio; LRP1, low-density lipoprotein receptor-related protein 1; PDGF, platelet-derived growth factor; SD, standard deviation

Key words: low-density lipoprotein receptor-related protein 1, genotypes, elderly, genders, mortality

\section{Introduction}

Cardiovascular diseases represent $>30 \%$ of all deaths worldwide in 2008 (1). Heart failure alone, one of the consequences of ischemic heart disease, leads to $\sim 2 \%$ of the health expenditure in the whole western world; therefore, the economic impact of cardiovascular diseases is huge. Therefore, it is important to identify at-risk patients early in order to optimize treatment and reduce costs. However, little is known regarding the association between genetic polymorphism and cardiovascular mortality risk.

Previous studies have shown a genetic association between single nucleotide polymorphisms (SNPs) and cardiovascular diseases. Special interest has been focused on the low-density lipoprotein receptor-related protein 1 (LRP1). In particular, the SNP rs1799986, of LRP1 is associated with increased rates of premature cardiovascular disease in familial hypercholesterolemia (2) and rs1466535 was identified in a genome-wide association study as a novel polymorphism associated with abdominal aortic aneurysm affecting the gene expression of LRP1 (3). According to Bown et al (3) functional analyses have demonstrated that rs1466535 might alter the sterol regulatory element-binding protein 1 binding site and therefore influence the activity at the locus.

Interestingly, the association between LRP1 and platelet-derived growth factor D (PDGF-D) was elucidated by Boucher et al (4). They demonstrated that LRP1 forms a complex of the PDGF receptor $\beta$ and that inactivation of LRP1 causes abnormal activation of PDGF with increased risk of atherosclerosis as a result. Therefore, as PDGF has been shown to be associated with vascular diseases and stroke (5), LRP1 is even more interesting to evaluate. Therefore, the aim of this study was to investigate the possible influence of polymorphisms in LRP1, rs1466535, on all-cause and cardiovascular (CV) mortality in an elderly primary health care population, and to identify possible gender differences as the latter has not been studied before.

\section{Materials and methods}

Patient population. The study population consisted of 489 individuals (men: 248; females: 241) with a mean age of 77.0 years (range: 18 years) living in a rural municipality in the south-east of Sweden, who were all part of a longitudinal 
epidemiological study focusing on CV risk factors (6). All the participants in that study were invited to participate in the present sub-study conducted from 13th January 2003 through 18th June 2005. The blood samples were collected at the University Hospital of Linköping (Linköping, Sweden). All those living in the municipality within a specific age bracket were invited to participate in the longitudinal project in order to minimize bias in the selection process. The population that agreed to participate donated blood samples and submitted to echocardiographic examinations and an electrocardiogram (ECG). The New York Heart Association functional class was evaluated by the on-site physician based on the patient information.

All participants gave their written informed consent and the study was conducted in accordance with the Declaration of Helsinki principles. The study protocol was approved by the Regional Ethical Review Board of Linköping, Sweden (Dnr 95044). Mortality information was obtained from autopsy reports or from the National Board of Health and Welfare in Sweden, which registers all deaths.

Co-morbidity. In this study the following definitions have been used; hypertension was defined as a blood pressure of $>140 / 90 \mathrm{mmHg}$ measured in the right arm with the patient in a supine position after at least $30 \mathrm{~min}$ rest. Hypertension was also assumed if the participant had previously been diagnosed with hypertension and was receiving antihypertensive medication. Diabetes mellitus was defined as a previous diagnosis with on-going treatment, or a fasting blood glucose $\geq 7 \mathrm{mmol} / 1$ measured on a single occasion. Ischemic heart disease was defined as a history of angina pectoris/myocardial infarction or ECG-verified myocardial infarction. Heart failure was defined as a previous diagnosis with on-going treatment, or symptoms/signs of heart failure and objective demonstration of reduced cardiac function in terms of impaired cardiac function on echocardiography. CV death was defined as death caused by fatal arrhythmias, myocardial infarction, heart failure, or cerebrovascular insult.

Ultrasound examinations. Echocardiography examinations were performed using an Accuson XP-128c with the patient in a left supine position. Values for systolic function were expressed as left ventricular ejection fraction (EF), and were split into four classes with interclass limits of 30, 40 and 50\%. Normal systolic function was defined as EF $\geq 50 \%$ (7-9). Thus, only the systolic function was evaluated.

The abdominal aorta was examined through routine ultrasound examination, using an Accuson XP-128c ultrasound machine.

Determination of LRP1 levels in plasma. All blood samples $(20 \mathrm{ml})$ were obtained while the patients were at rest in a supine position and all samples were collected in pre-chilled plastic Vacutainer tubes (Terumo EDTA K-3); however, $2 \mathrm{ml}$ was used for subsequent analysis. Plasma was prepared by centrifugation at $3,000 \mathrm{xg}$ for $10 \mathrm{~min}$ at $4^{\circ} \mathrm{C}$. All samples were stored at $-70^{\circ} \mathrm{C}$ until used for analysis. None of the samples were thawed more than twice.

Plasma levels of LRP1 were measured using a commercially available ELISA kit (Cloud-Clone Corporation, Houston, TX,
USA) following the manufacturer's protocol. Plasma samples were diluted 1:2,000.

Genotype determination. Genomic DNA was isolated from peripheral blood using the QIAmp DNA Mini kit (Qiagen $\mathrm{GmbH}$, Hilden, Germany), following the manufacturer's protocol. Genomic determination was performed as described in the literature (10). Briefly, DNA (10 ng) was mixed with TaqMan genotyping master mix coding rs1466535 in LRP1 gene (assay ID: C 7499211 10; Applied Biosystems; Thermo Fisher Scientific, Inc.) and with TaqMan Universal PCR Master mix II. The 7500 Fast Real-Time PCR system (Applied Biosystems; Thermo Fisher Scientific, Inc.) was used with initial cycle at $50^{\circ} \mathrm{C}$ for $2 \mathrm{~min}$, followed by one cycle at $95^{\circ} \mathrm{C}$ for $10 \mathrm{~min}$ and 40 cycles at $95^{\circ} \mathrm{C}$ for $15 \mathrm{sec}$ and at $60^{\circ} \mathrm{C}$ for $1 \mathrm{~min}$. The manual calling option in the allelic discrimination application ABI PRISM 7500 SDS software, version 1.3.1 (Applied Biosystems; Thermo Fisher Scientific, Inc.) was then used to assign the genotypes.

Statistical methods. Descriptive data are presented as percentages or mean and standard deviation (SD). Comparative analyses were performed using the Student's unpaired two-sided t-test, whereas the Chi-square test was used for discrete variables. Both univariate and multivariate Cox proportional hazard regression analyses were used to analyze and illustrate the risk of mortality during the follow-up period, where both all-cause mortality and CV mortality were analyzed. Kaplan-Meier graphs were used to illustrate $\mathrm{CV}$ mortality as a function of follow-up time. Censored patients were those who were still alive at the end of the study period or who had died of causes other than CV disease. Completed patients comprised those who had died due to $\mathrm{CV}$ disease. In the multivariate multivariable regression model, adjustments were made for the following co-variates: Age, hypertension, ischemic heart disease, diabetes, atrial fibrillation, $\mathrm{Hb}<120 \mathrm{~g} / \mathrm{l}, \mathrm{EF}<40 \%$, ACE-inhibitors/Angiotensin receptor blockers, beta-blockers, diuretics, s-cholesterol, s-triglycerides, s-low density lipoporotein (LDL) and s-high density lipoporoteins (HDL).

In the Cox regressions, the $\mathrm{C} / \mathrm{T}$ and $\mathrm{T} / \mathrm{T}$ genotypes were amalgamated because almost identical mortality figures were found during the follow-up with the two groups, and because the group size of the $\mathrm{T} / \mathrm{T}$ group was small.

$\mathrm{P}<0.05$ was considered to indicate a statistically significant difference. All data were analyzed using standard software packages (Statistica v. 13.1; Statsoft, Inc., Tulsa, OK, USA).

\section{Results}

The basic characteristics of the study population divided into gender and genotypes of LPR1 are presented in Table I.

Almost equal numbers of males and females were included (237 vs. 252 ). In the total study population, $383 / 489$ (78.3\%) of the participants had hypertension, $116 / 489$ (23.7\%) had diabetes, 115/489 (23.5\%) had ischemic heart disease and 134/489 (27.4\%) were receiving treatment with ACE-inhibitors or angiotensin receptor blockers. Of the population, 187/489 $(38.2 \%)$ were receiving treatment with beta-blockers and $175 / 489$ (35.8\%) were receiving treatment with diuretics. 
Table I. Basal characteristics of the study population divided into the three polymorphisms of LRP1.

\begin{tabular}{|c|c|c|c|c|}
\hline \multirow[b]{2}{*}{ Variable } & \multicolumn{3}{|c|}{ LRP1 } & \multirow[b]{2}{*}{ P-value } \\
\hline & TT & $\mathrm{CT}$ & $\mathrm{CC}$ & \\
\hline $\mathrm{n}$ & 65 & 222 & 202 & \\
\hline Males/females, $\mathrm{n}$ & $25 / 40$ & $107 / 115$ & $105 / 97$ & \\
\hline Age, mean (SD) & $77.4(4.0)$ & $77.3(3.6)$ & $77.7(3.9)$ & \\
\hline \multicolumn{5}{|l|}{ History } \\
\hline Diabetes, n (\%) & $13(20.0)$ & $56(25.2)$ & $47(23.3)$ & 0.66 \\
\hline Hypertension, n (\%) & $49(75.4)$ & $171(77.0)$ & $163(80.7)$ & 0.99 \\
\hline $\mathrm{IHD}, \mathrm{n}(\%)$ & $12(18.5)$ & $52(23.4)$ & $51(25.2)$ & 0.53 \\
\hline NYHA I, n (\%) & $33(50.8)$ & $112(50.5)$ & $95(47.0)$ & 0.75 \\
\hline NYHA II, n (\%) & $17(26.2)$ & $67(30.2)$ & $72(35.6)$ & 0.27 \\
\hline NYHA III, n (\%) & $13(20.0)$ & $41(18.5)$ & $35(17.3)$ & 0.88 \\
\hline NYHA IV, n (\%) & $2(3.1)$ & $1(0.5)$ & 0 & \\
\hline Unclassified, n & 0 & $1(0.5)$ & 0 & \\
\hline \multicolumn{5}{|l|}{ Medication } \\
\hline Beta blockers, n (\%) & $24(37)$ & $70(32)$ & $93(46)$ & 0.08 \\
\hline ACEI/AII, n (\%) & $12(19)$ & $57(26)$ & $65(32)$ & 0.07 \\
\hline Diuretics, n (\%) & $21(32)$ & $81(36)$ & $73(36)$ & 0.81 \\
\hline \multicolumn{5}{|l|}{ Examinations } \\
\hline BP, systolic mm Hg, mean (SD) & $151(20)$ & $148(24)$ & $150(19)$ & 0.62 \\
\hline $\mathrm{BP}$, diastolic mmHg, mean (SD) & $75(10)$ & $75(12)$ & $75(10)$ & 0.97 \\
\hline IMT, thickness, mm (SD) & $0.61(0.22)$ & $0.54(0.16)$ & $0.59(0.18)$ & 0.02 \\
\hline $\mathrm{EF}<40 \%, \mathrm{n}(\%)$ & $5(8)$ & $14(6)$ & $20(10)$ & 0.31 \\
\hline
\end{tabular}

ACEI, ACE inhibitor; AII, Angiotensin receptor blockers; BP, Blood pressure; EF, Ejection fraction; IHD, ischemic heart disease; IMT, intima media thickness; NYHA, New York Heart Association functional class; LRP1, low-density lipoprotein receptor-related protein 1; SD, standard deviation.

The abdominal aorta of in the study population was examined and a systolic dimension between 29.3 to $9.7 \mathrm{~mm}$ was found. Based on these measurements there were no signs of abdominal aortic aneurysms in the individuals examined.

When analyzing the two genders, it was found that significantly more females with the $\mathrm{C} / \mathrm{T}$ genotype were receiving treatment with diuretics compared with the corresponding genotype among males ( $47.2 \%$ vs. $26.3 \%$; $\mathrm{P}=0.001)$, which is in concurrence with other gender-divided reports (6). In the population with the $\mathrm{C} / \mathrm{C}$ genotype, a higher systolic blood pressure was recorded among the females compared with the males with the same genotype. Also, it could be demonstrated that there was a larger proportion of participants with an impaired heart function out of the male population with the genotypes $\mathrm{C} / \mathrm{T}$ and $\mathrm{C} / \mathrm{C}$, compared with the females with the corresponding genotypes.

Plasma levels of LRPI. In a small subsection of the study population $(n=221)$ the level of LRP1 was evaluated using an ELISA. When evaluating the three genotypes, it could also be seen that the $\mathrm{C} / \mathrm{C}$ genotype had a reduced level of LRP1 in comparison with the T/T genotype [mean 20,994 (SD 7131) pg/ml vs. 23,409 (SD 5651) $\mathrm{pg} / \mathrm{ml} ; \mathrm{P}=0.043$ ) and the $\mathrm{C} / \mathrm{T}$ genotype with a level mean 21534 (SD 7,969) pg/ml]. No other differences in levels of LRP1 between clinical or gender groups could be found.
Mortality and genotypes. The median follow-up time of the population was 80 months (6.7 years) and during that time $116(23.7 \%)$ all-cause and $75(15.3 \%)$ CV deaths were registered. Analyzing the three genotypes and the total number of mortalities, significant differences could be detected in the distribution of both all-cause and CV mortality, with a higher mortality in the male population with the $\mathrm{C} / \mathrm{C}$ genotype (Table II).

In a survival analysis, no significant difference in survival could be demonstrated between the three genotypes in the total study population, nor in the male population (Fig. 1).

However, evaluating the female population revealed significant differences in survival between the three genotypes, where increased all-cause mortality could be seen in the $\mathrm{T} / \mathrm{T}$ and $\mathrm{C} / \mathrm{T}$ genotypes $(\mathrm{P}<0.05$; Fig. 2$)$.

Analyzing mortality risk during the 6.7 years of follow-up in a multivariate model demonstrated a significantly increased risk both of all-cause mortality (HR 1.68; 95\% CI 1.12-2.52; $\mathrm{P}=0.01$ ) and $\mathrm{CV}$ mortality (HR 2.07; 95\% CI 1.23-3.49; $\mathrm{P}=0.006$ ) of the total study population for those with the $\mathrm{T} / \mathrm{T}$ or C/T genotype (Table III).

Evaluating the female population with the same multivariate model showed increased risk for all-cause mortality (HR 2.75; 95\% CI 1.28-5.90; $\mathrm{P}=0.01$ ) and for CV mortality (HR 5.61; 95\% CI 1.98-15.85; $\mathrm{P}=0.001$ ) for those with the $\mathrm{T} / \mathrm{T}$ 
Table II. Cardiovascular and all-cause mortality in the study population distributed in the three genotypes of LRP1, and gender, during a follow-up period of 80 months.

\begin{tabular}{|c|c|c|c|c|c|c|}
\hline \multirow[b]{2}{*}{ LRP1 } & \multicolumn{3}{|c|}{ CV mortality } & \multicolumn{3}{|c|}{ All-cause mortality } \\
\hline & Females & Males & P-value & Females & Males & P-value \\
\hline $\mathrm{C} / \mathrm{C}, \mathrm{n}(\%)$ & $14 / 97(14.4)$ & $32 / 105(30.5)$ & $\begin{array}{l}X^{2}=7.38 \\
P=0.007\end{array}$ & 22/97 (22.7) & $47 / 105(44.8)$ & $\begin{array}{c}\mathrm{X}^{2}=10.9 \\
\mathrm{P}=0.0009\end{array}$ \\
\hline $\mathrm{C} / \mathrm{T}, \mathrm{n}(\%)$ & 20/115 (17.4) & 21/107 (19.6) & $\mathrm{P}=0.67$ & $35 / 115(30.4)$ & 37/107 (34.6) & 0.51 \\
\hline $\mathrm{T} / \mathrm{T}, \mathrm{n}(\%)$ & $6 / 40(15.0)$ & $7 / 25(28.0)$ & 0.20 & $9 / 40(23.0)$ & $11 / 25(44.0)$ & 0.07 \\
\hline
\end{tabular}

As the $\mathrm{T} / \mathrm{T}$ genotype was small, the two genotype groups $\mathrm{T} / \mathrm{T}$ and $\mathrm{C} / \mathrm{T}$ were amalgamated into one group in the further mortality evaluations. LRP1, low-density lipoprotein receptor-related protein 1; CV, cardiovascular.

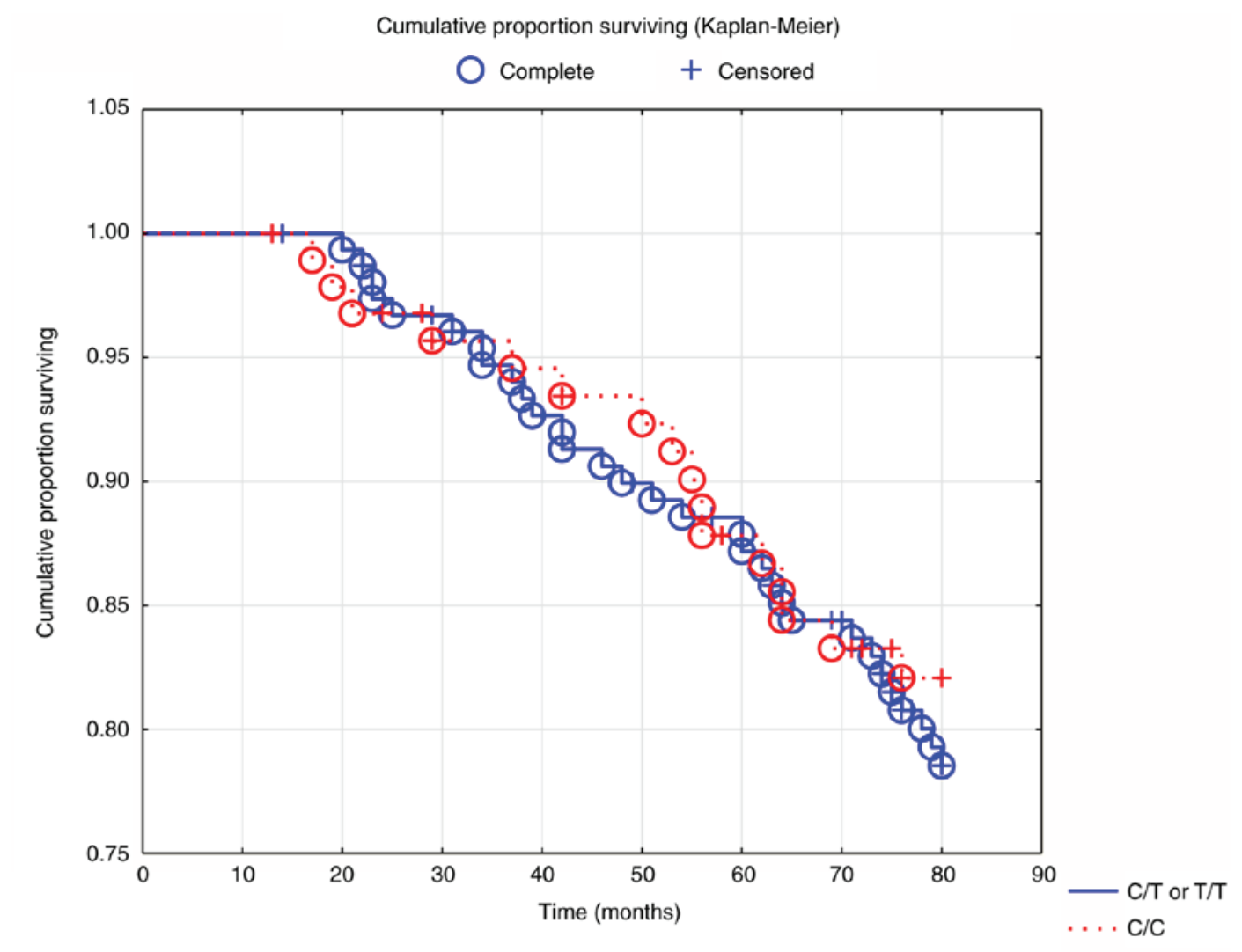

$\mathrm{Z}=0.49, \mathrm{P}=0.62$

Figure 1. Kaplan-Meier analysis illustrating all-cause mortality in those with the low-density lipoprotein receptor-related protein 1 genotypes T/T or C/T vs. $\mathrm{C} / \mathrm{C}$ in an elderly male population during a follow-up period of 80 months. Note: Censored participants were those still living at the end of the study period, or who had died for reasons other than cardiovascular disease. Completed participants were those who had died due to cardiovascular disease.

or $\mathrm{C} / \mathrm{T}$ genotypes, as compared to those with the $\mathrm{C} / \mathrm{C}$ genotype (Table IV).

No corresponding increased risk could be seen in the male population (for all-cause mortality HR 1.19; 95\% CI 0.72-1.97; $\mathrm{P}=0.49$; for $\mathrm{CV}$ mortality HR 1.39; 95\% CI 0.74-2.60; $\mathrm{P}=0.31$ ).

\section{Discussion}

In this study three genotypes of LRP1 were evaluated; $\mathrm{C} / \mathrm{C}$, $\mathrm{C} / \mathrm{T}$ and $\mathrm{T} / \mathrm{T}$, and different risks of both all-cause, and $\mathrm{CV}$ mortality were demonstrated in different genotypes of the female population, but not in males. It should be noted that the population evaluated in this study was an elderly community-living group and there, a representative one even though the sample size was not large. The results are interesting as they show gender-specific differences both regarding all-cause and to a greater extent CV mortality. The main project has been presented in several previous publications (11-22).

That genetic variance could result in effects on $\mathrm{CV}$-associated mortality is well-known from the literature (23-25).

However, to the best of our knowledge, this is the first time that differences in gender-specific risk in mortality that are associated with a genetic variance have been demonstrated. 


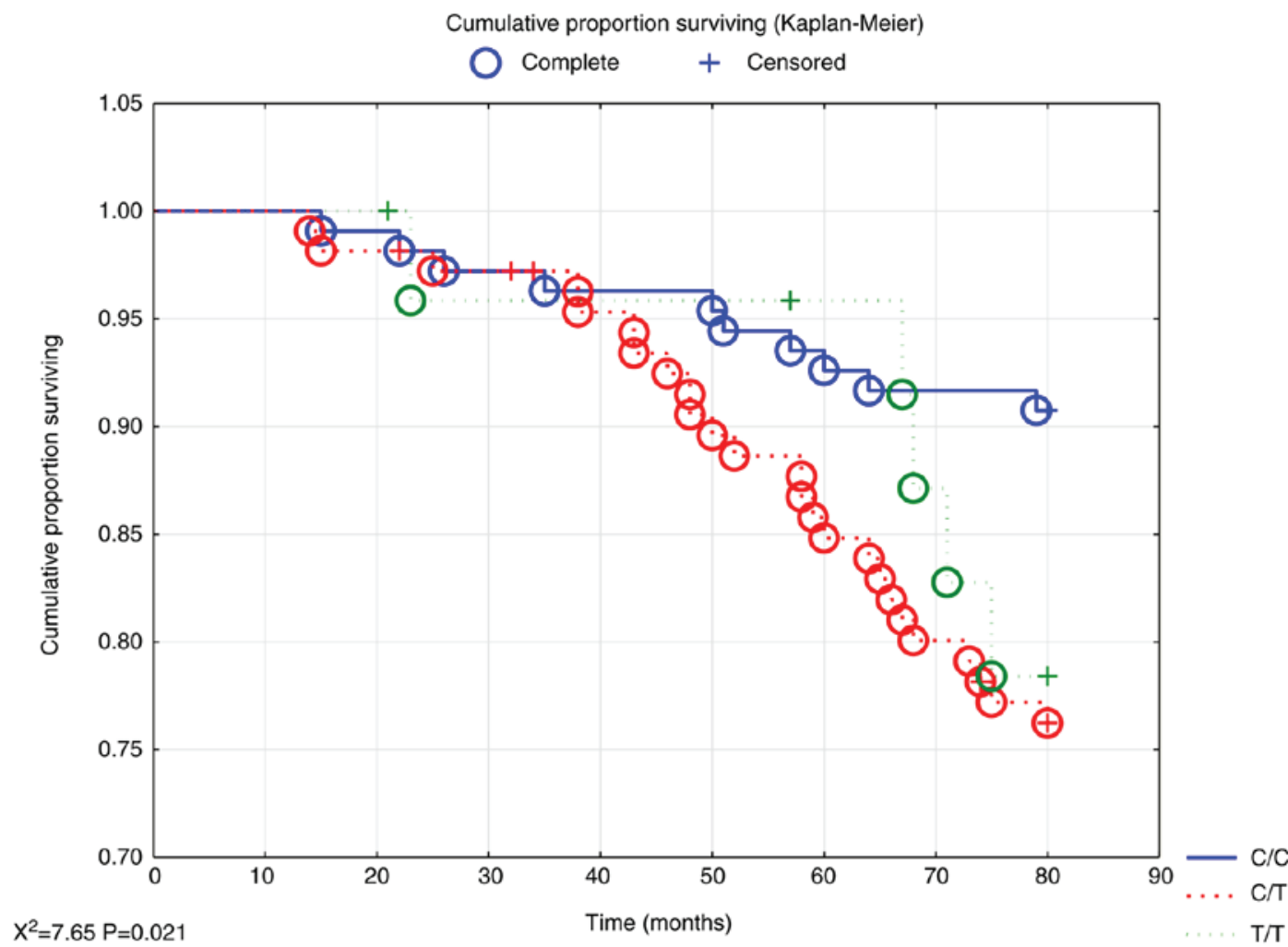

Figure 2. Kaplan-Meier analysis illustrating all-cause mortality in those with the low-density lipoprotein receptor-related protein 1 genotypes $\mathrm{T} / \mathrm{T}$ or $\mathrm{C} / \mathrm{T}$ or $\mathrm{C} / \mathrm{C}$ in an elderly female population during a follow-up period of 80 months. Note: Censored participants were those still living at the end of the study period, or who had died for reasons other than cardiovascular disease. Completed participants were those who had died due to cardiovascular disease.

In recent years, special interest has been focused on LRP1 and its possible association with CV diseases. Gonias (26) demonstrated in an excellent review the important relationship between LRP1 and smooth muscle cell properties. In a report from Italy, Galora et al (27) demonstrated an interesting association between the $\mathrm{T}$ allele of rs1466535 and abdominal aortic aneurysms, but not with the other alleles investigated. The present study was able to confirm that the $\mathrm{T}$ allele also had an association with mortality, but only in one of the two genders. Ye et al (28) in a study of abdominal aneurysms, demonstrated significant sex differences, where a faster expansion of the aneurysms could be seen in the female group and therefore the present study intended to evaluate any sex differences in CV mortality in the different genotypes of rs1466535.

As Giusti et al (29) reported, the present study also found that the majority of participants had the $\mathrm{C} / \mathrm{C}$ genotype and only a small number had the T/T genotype. After combining the $\mathrm{T} / \mathrm{T}$ and the $\mathrm{C} / \mathrm{T}$ genotypes, Giusti was able to report a greater proportion of patients suffering from carotid stenosis in this group compared with the $\mathrm{C} / \mathrm{C}$ genotype. The same amalgamating process of the $\mathrm{T} / \mathrm{T}$ and $\mathrm{C} / \mathrm{T}$ genotypes in the evaluations was performed in the present study.

In the literature there are reports of a study with a larger number of participants compared to the present study, such as the huge genome-wide association study for coronary artery disease reported by Webb et al (30), which included more than 120,000 participants. However, the important difference compared with the present study is that mortality data for all participants is included; no one was lost during the follow-up period of 6.7 years. CV mortality is regarded as the definite endpoint of the CV risks that the participants were exposed to, rather than getting diagnosed with coronary artery disease, as was done in the genome-wide association study mentioned above, which is why the small study sample reported in the present study is notable.

In the ELISA evaluation of the levels of LRP1, a significant difference was demonstrated in the levels between the T/T and the $\mathrm{C} / \mathrm{C}$ genotypes, a fact that has not been reported before to the best of our knowledge. In the genome-wide study by Bown et al they reported a tendency toward an increased level of the C/C genotype of LRP1 in comparison with the T/T genotype (3). However, Bown et al reported on a population with abdominal aortic aneurysms, something that the population of the present study did not have and thus it is not surprising that the opposite results were reported regarding the level of the C/C genotype of LRP1.

The female population of individuals with the $\mathrm{T} / \mathrm{T}$ or $\mathrm{C} / \mathrm{T}$ genotypes of LRP1 demonstrated a 2.75 -fold increased risk of all-cause mortality and a 5.61-fold increased risk of CV mortality when applying a multivariate model adjusting for certain well-known variables influencing the CV mortality risk. However, it should be pointed out that the confidence interval is wide in the evaluation, so it is important to interpret the point estimate of the HR with caution. The wide confidence interval is probably the result of the limited size of the different genotype groups analyzed. The important message is that an increased mortality risk exists in the $\mathrm{C} / \mathrm{T}$ and $\mathrm{T} / \mathrm{T}$ genotypes in comparison with the $\mathrm{C} / \mathrm{C}$ genotype. In the male population no such prognostic differences between the different genotypes of LRP1 could be found. This could imply that irrespective of 
Table III. Multivariate Cox proportional hazard regression illustrating risk of cardiovascular and all-cause mortality in the total population and with a follow-up period of 80 months.

\begin{tabular}{|c|c|c|c|c|c|c|}
\hline \multirow[b]{2}{*}{ Variables } & \multicolumn{3}{|c|}{ CV-mortality } & \multicolumn{3}{|c|}{ All cause mortality } \\
\hline & $\begin{array}{l}\text { Hazard } \\
\text { ratio }\end{array}$ & $\begin{array}{c}95 \% \text { confidence } \\
\text { interval }\end{array}$ & P-value & $\begin{array}{l}\text { Hazard } \\
\text { ratio }\end{array}$ & $\begin{array}{c}95 \% \text { confidence } \\
\text { interval }\end{array}$ & P-value \\
\hline Age & 1.07 & $1.00-1.15$ & 0.04 & 1.06 & $1.01-1.12$ & 0.02 \\
\hline Hypertension & 1.34 & $0.75-2.40$ & 0.32 & 1.61 & $0.99-2.61$ & 0.06 \\
\hline IHD & 1.21 & $0.70-2.11$ & 0.50 & 1.34 & $0.85-2.09$ & 0.21 \\
\hline Atrial fibrillation & 2.39 & $1.29-4.46$ & 0.006 & 2.27 & $1.37-3.76$ & 0.001 \\
\hline Diabetes & 1.64 & $0.97-2.77$ & 0.07 & 1.51 & $0.98-2.32$ & 0.06 \\
\hline $\mathrm{Hb}<120 \mathrm{~g} / \mathrm{l}$ & 1.69 & $0.90-3.17$ & 0.10 & 1.26 & $0.71-2.22$ & 0.43 \\
\hline $\mathrm{EF}<40 \%$ & 1.72 & $0.82-3.57$ & 0.15 & 1.81 & $1.02-3.23$ & 0.04 \\
\hline ACEI/ARB & 0.79 & $0.46-1.38$ & 0.41 & 0.75 & $0.48-1.18$ & 0.21 \\
\hline Beta blockers & 1.27 & $0.76-2.10$ & 0.36 & 1.09 & $0.72-1.65$ & 0.67 \\
\hline Diuretics & 1.00 & $0.60-1.69$ & 0.99 & 1.09 & $0.72-1.65$ & 0.69 \\
\hline s-Chol & 0.59 & $0.02-22.4$ & 0.78 & 0.83 & $0.19-3.54$ & 0.80 \\
\hline s-Triglyc & 0.99 & $0.18-5.36$ & 0.99 & 0.86 & $0.40-1.82$ & 0.69 \\
\hline s-LDL & 1.73 & $0.04-66.7$ & 0.77 & 1.11 & $0.26-4.74$ & 0.89 \\
\hline s-HDL & 1.49 & $0.04-54.4$ & 0.83 & 1.08 & $0.23-5.04$ & 0.92 \\
\hline LRP1 $\mathrm{C} / \mathrm{T}$ or $\mathrm{T} / \mathrm{T}$ & 2.07 & $1.23-3.49$ & 0.006 & 1.68 & $1.12-2.52$ & 0.01 \\
\hline
\end{tabular}

ACEI/ARB, ACE-inhibitors, or Angiotensin receptor blockers; EF, Ejection fraction based on echocardiography; IHD, ischemic heart disease; s-Chol, s-Cholesterol, mmol/l; s-HDL, s-High Density Lipoproteins, mmol/l; s-LDL, s-Low Density Lipoproteins, mmol/l; s-Triglyc: s-Triglycerides, mmol/l; LRP1, low-density lipoprotein receptor-related protein 1; Hb, hemoglobin.

Table IV. Multivariate Cox proportional hazard regression illustrating risk of cardiovascular and all-cause mortality in the female population and with a follow-up period of 80 months.

\begin{tabular}{|c|c|c|c|c|c|c|}
\hline \multirow[b]{2}{*}{ Variables } & \multicolumn{3}{|c|}{ CV-mortality } & \multicolumn{3}{|c|}{ All cause mortality } \\
\hline & $\begin{array}{l}\text { Hazard } \\
\text { ratio }\end{array}$ & $\begin{array}{c}95 \% \text { confidence } \\
\text { interval }\end{array}$ & P-value & $\begin{array}{l}\text { Hazard } \\
\text { ratio }\end{array}$ & $\begin{array}{l}95 \% \text { confidence } \\
\text { interval }\end{array}$ & P-value \\
\hline Age & 0.98 & $0.88-1.10$ & 0.77 & 1.04 & $0.95-1.15$ & 0.38 \\
\hline Hypertension & 1.18 & $0.43-3.23$ & 0.74 & 1.29 & $0.56-2.98$ & 0.55 \\
\hline IHD & 1.69 & $0.60-4.77$ & 0.32 & 1.90 & $0.86-4.19$ & 0.11 \\
\hline Atrial fibrillation & 3.38 & $0.95-12.00$ & 0.06 & 2.41 & $0.89-6.53$ & 0.08 \\
\hline Diabetes & 3.23 & $1.26-8.30$ & 0.01 & 1.99 & $0.95-4.14$ & 0.07 \\
\hline $\mathrm{Hb}<120 \mathrm{~g} / \mathrm{l}$ & 4.12 & $1.62-10.51$ & 0.03 & 2.57 & $1.11-5.94$ & 0.03 \\
\hline $\mathrm{EF}<40 \%$ & 2.14 & 0.41 .11 .08 & 0.36 & 0.90 & $0.19-4.35$ & 0.90 \\
\hline ACEI/ARB & 0.60 & $0.22-1.65$ & 0.32 & 1.08 & $0.50-2.32$ & 0.85 \\
\hline Beta blockers & 1.40 & $0.56-3.48$ & 0.47 & 1.09 & $0.53-2.24$ & 0.81 \\
\hline Diuretics & 2.04 & $0.81-5.15$ & 0.13 & 1.85 & $0.86-3.98$ & 0.11 \\
\hline s-Chol & 1.08 & $0.19-6.15$ & 0.93 & 0.89 & $0.20-4.01$ & 0.88 \\
\hline s-Triglyc & 1.17 & $0.37-3.76$ & 0.79 & 0.98 & $0.36-2.68$ & 0.96 \\
\hline s-LDL & 0.91 & $0.16-5.07$ & 0.91 & 0.93 & $0.24-4.74$ & 0.93 \\
\hline s-HDL & 2.82 & $0.35-22.91$ & 0.33 & 1.56 & $0.26-9.48$ & 0.63 \\
\hline LRP1 $\mathrm{C} / \mathrm{T}$ or $\mathrm{T} / \mathrm{T}$ & 5.61 & $1.98-15.85$ & 0.001 & 2.75 & $1.28-5.90$ & 0.01 \\
\hline
\end{tabular}

ACEI/ARB, ACE-inhibitors, or Angiotensin receptor blockers; EF, Ejection fraction based on echocardiography; IHD, ischemic heart disease; s-Chol, s-Cholesterol, mmol/l; s-HDL, s-High Density Lipoproteins, mmol/1; s-LDL, s-Low Density Lipoproteins, mmol/l; s-Triglyc, s-Triglycerides, mmol/1; LRP1, low-density lipoprotein receptor-related protein 1; Hb, hemoglobin. 
the LRP1 genotype, there are stronger factors that determine the mortality risk in the male group, for example mortality based on ischemic heart disease, a condition with a substantial preponderance in the male population.

In the literature there are a multitude of reports indicating that there are gender differences regarding CV mortality in general and a higher mortality is generally reported in the male population of corresponding age, compared to the female population $(31,32)$. The major reason for this is the higher incidence of ischemic heart disease among males (33). It is possible that the SNP may in some (secondary) way be influenced by variation in genes situated on the sex chromosomes, or by hormonal differences between men and women, and this should be a focus of further study.

The presented gender differences in some of the genotypes of LRP1 are of importance in clinical routine since individuals with increased risk for CV mortality can be identified. Even if it is not possible to modify the genetic constitution, it is possible to provide more intense prevention procedures and an individualized follow-up program for patients, which also may reduce $\mathrm{CV}$ mortality and health care costs.

It should also be noted that the genetic analyses exhibited in the present study were conducted at a cost that was below the cost for analyses of the golden-standard biomarker used to identify patients with heart failure, the N-terminal fragment of the natriuretic peptide proBNP. Thus, it was concluded that the presented genetic analyses are also cost-effective in the clinic.

It could be argued that it would only be relevant to evaluate the at-risk genotypes in an at-risk population. However, this assumption is only correct in a population with known or assumed increased risk and this is usually not the case in the clinical routine. Therefore, elderly persons from a community-living population with mixed $\mathrm{CV}$ risks were included to better reflect the situation that clinicians are faced with every day. Despite this fact, it was possible to obtain significant and interesting data indicating that certain individuals are exposed to an increased risk that can be identified through genotype evaluation.

Therefore, out of the female group, those with the $\mathrm{C} / \mathrm{T}$ or T/T genotypes of the LPR1 gene, with a more than 5-fold increased risk of $\mathrm{CV}$ mortality, constituted a high-risk population and thus it was important to identify them, even though the obtained point estimate should be interpreted with caution due to the limited sample size.

However, from a clinical and economical point of view it is also interesting to identify those with a low risk of mortality. As the present study demonstrated above, the females with the C/C genotype of LRP1 only exhibited a 9.3\% all-cause and a $4.6 \% \mathrm{CV}$ mortality during almost seven years of follow-up in spite of being an elderly patient group. From this it could be concluded that identifying both those at high as well as those at low risk of death is important from a clinical point of view and the use of genetic information could further aid in this identification process.

The presented research is a community-based study and thus includes most patients with discrete or no CV symptoms. Therefore, those with CV disease are in a minority and thus the size of the $\mathrm{CV}$ group is small, which results in wide CIs in risk evaluations, thus making their interpretation uncertain.
Also, the presented study population is an elderly one and therefore it is not possible to extrapolate the obtained results into other age groups without uncertainty.

Finally, as the subgroups of those with certain genotypes are small, the results of some of the evaluations should be interpreted with caution and the results should be regarded as hypothesis-generating. However, the results of the present study are in line with and strengthen previous findings and a hypothesis that the investigated genes and SNPs could play an important role as markers to identify individuals at risk.

In conclusion, information regarding the LRP1 gene was applied to an elderly primary health care population that was followed for almost seven years and where all mortality was registered. Specific gender differences were noted, and in the female group those with the LRP1 $\mathrm{T} / \mathrm{T}$ or $\mathrm{C} / \mathrm{T}$ genotype had a 5.61-fold increased risk for $\mathrm{CV}$ mortality in the multivariate analysis.

In the male group however, no such gender difference could be found.

Applying a combined analysis using, for the females, those with LRP1 C/T or T/T could substantially increase the possibility of identifying individuals with high $\mathrm{CV}$ risk and thereby help to optimize CV prevention and treatment.

\section{Acknowledgements}

The authors would like to thank research nurse Mrs. Anette Gylling for all her valuable help in preparation of the blood samples.

\section{Funding}

The present study was supported by grants from the County Council of Östergötland, University of Linköping, Linköping, Sweden and the Swedish Heart and Lung Foundation.

\section{Availability of data and materials}

Under Swedish Law, the datasets generated/analyzed are not publicly available but are available from the corresponding author upon reasonable request and with permission of the University of Linköping.

\section{Authors' contributions}

Conceived and designed the experiments: UA and DW; performed the experiments: UA and DW; analyzed the data: UA and DW; contributed reagents/material/analysis tools: DW; wrote the manuscript: UA and DW.

\section{Ethics approval and consent to participate}

All participants gave their written informed consent and the study was conducted in accordance with the Declaration of Helsinki principles. The study protocol was approved by the Regional Ethical Review Board of Linköping, Sweden (Dnr 95044).

\section{Patient consent for publication}

All participants gave their written informed consent. 


\section{Competing interests}

The authors declare that they have no competing interests.

\section{References}

1. Alwan A: Global report on noncommunicable diseases 2010. Italy, World Health Organization, 2011

2. Aledo R, Alonso R, Mata P, Llorente-Cortés V, Padró T and Badimon L: LRP1 gene polymorphisms are associated with premature risk of cardiovascular disease in patients with familial hypercholesterolemia. Rev Esp Cardiol (Engl Ed) 65: 807-812, 2012 (In English, Spanish)

3. Bown MJ, Jones GT, Harrison SC, Wright BJ, Bumpstead S, Baas AF, Gretarsdottir S, Badger SA, Bradley DT, Burnand $\mathrm{K}$, et al: Abdominal aortic aneurysm is associated with a variant in low-density lipoprotein receptor-related protein 1 . Am J Hum Genet 89: 619-627, 2011.

4. Boucher P, Gotthardt M, Li WP, Anderson RG and Herz J: LRP: Role in vascular wall integrity and protection from atherosclerosis. Science 300: 329-332, 2003.

5. Folestad E, Kunath A and Wågsäter D: PDGF-C and PDGF-D signaling in vascular diseases and animal models. Mol Aspects Med 62: 1-11, 2018.

6. Alehagen U, Ericsson A and Dahlström U: Are there any significant differences between females and males in the management of heart failure? Gender aspects of an elderly population with symptoms associated with heart failure. J Card Fail 15: 501-507, 2009.

7. Pombo JF, Troy BL and Russell RO Jr: Left ventricular volumes and ejection fraction by echocardiography. Circulation 43: 480-490, 1971

8. Wahr DW, Wang YS and Schiller NB: Left ventricular volumes determined by two-dimensional echocardiography in a normal adult population. J Am Coll Cardiol 1: 863-868, 1983.

9. Gibbons RJ, Lee KL, Cobb F and Jones RH: Ejection fraction response to exercise in patients with chest pain and normal coronary arteriograms. Circulation 64: 952-957, 1981.

10. Shamoun L, Skarstedt M, Andersson RE, Wågsäter D and Dimberg J: Association study on IL-4, IL-4R $\alpha$ and IL-13 genetic polymorphisms in Swedish patients with colorectal cancer. Clin Chim Acta 487: 101-106, 2018

11. Ljungberg L, Alehagen U, Länne T, Björck H, De Basso R, Dahlström U and Persson K: The association between circulating angiotensin-converting enzyme and cardiovascular risk in the elderly: A cross-sectional study. J Renin Angiotensin Aldosterone Syst 12: 281-289, 2011.

12. Björck HM, Länne T, Alehagen U, Persson K, Rundkvist L, Hamsten A, Dahlström U and Eriksson P: Association of genetic variation on chromosome 9p21.3 and arterial stiffness. J Intern Med 265: 373-381, 2009.

13. Ljungberg LU, De Basso R, Alehagen U, Björck HM, Persson K, Dahlström U and Länne T: Impaired abdominal aortic wall integrity in elderly men carrying the angiotensin-converting enzyme D allele. Eur J Vasc Endovasc Surg 42: 309-319, 2011

14. Johansson P, Alehagen U, Ulander M, Svanborg E, Dahlström U and Broström A: Sleep disordered breathing in community dwelling elderly: Associations with cardiovascular disease impaired systolic function, and mortality after a six-year follow-up. Sleep Med 12: 748-753, 2011.

15. Chisalita SI, Dahlström U, Arnqvist HJ and Alehagen U: Increased IGF1 levels in relation to heart failure and cardiovascular mortality in an elderly population: Impact of ACE inhibitors. Eur J Endocrinol 165: 891-898, 2011.

16. Johansson P, Alehagen U, Svanborg E, Dahlström U and Broström A: Clinical characteristics and mortality risk in relation to obstructive and central sleep apnoea in community-dwelling elderly individuals: A 7-year follow-up. Age Ageing 41: 468-474, 2012.

17. Ljungberg LU, Alehagen U, De Basso R, Persson $\mathrm{K}$, Dahlström $U$ and Länne T: Circulating angiotensin-converting enzyme is associated with left ventricular dysfunction, but not with central aortic hemodynamics. Int J Cardiol 166: 540-541, 2013.

18. Johansson P, Riegel B, Svensson E, Broström A, Alehagen U, Dahlström U and Jaarsma T: The contribution of heart failure to sleep disturbances and depressive symptoms in older adults. J Geriatr Psychiatry Neurol 25: 179-187, 2012.
19. Johansson P, Riegel B, Svensson E, Broström A, Alehagen U, Dahlström U and Jaarsma T: Sickness behavior in community-dwelling elderly: Associations with impaired cardiac function and inflammation. Biol Res Nurs 16: 105-113, 2014.

20. Johansson P, Svensson E, Alehagen U, Jaarsma T and Broström A: The contribution of hypoxia to the association between sleep apnoea, insomnia, and cardiovascular mortality in community-dwelling elderly with and without cardiovascular disease. Eur J Cardiovasc Nurs 14: 222-231, 2015.

21. Chisalita SI, Dahlström U, Arnqvist HJ and Alehagen U: Proinsulin and IGFBP-1 predicts mortality in an elderly population. Int J Cardiol 174: 260-267, 2014.

22. Alehagen U, Vorkapic E, Ljungberg L, Länne T and Wågsäter D: Gender difference in adiponectin associated with cardiovascular mortality. BMC Med Genet 16: 37, 2015.

23. Eppinga RN, Hagemeijer Y, Burgess S, Hinds DA, Stefansson K, Gudbjartsson DF, van Veldhuisen DJ, Munroe PB, Verweij N and van der Harst P: Identification of genomic loci associated with resting heart rate and shared genetic predictors with all-cause mortality. Nat Genet 48: 1557-1563, 2016.

24. Ansani L, Marchesini J, Pestelli G, Luisi GA, Scillitani G, Longo G, Milani D, Serino ML, Tisato V and Gemmati D: F13A1 gene variant (V34L) and residual circulating FXIIIA levels predict Short- and Long-term mortality in acute myocardial infarction after coronary angioplasty. Int J Mol Sci 19: pii: E2766, 2018

25. Heijmans BT, Westendorp RG, Knook DL, Kluft C and Slagboom PE: Angiotensin I-converting enzyme and plasminogen activator inhibitor-1 gene variants: Risk of mortality and fatal cardiovascular disease in an elderly population-based cohort. J Am Coll Cardiol 34: 1176-1183, 1999.

26. Gonias SL: Mechanisms by which LRP1 (Low-Density Lipoprotein Receptor-Related Protein-1) maintains arterial integrity. Arterioscler Thromb Vasc Biol 38: 2548-2549, 2018.

27. Galora S, Saracini C, Pratesi G, Sticchi E, Pulli R, Pratesi C, Abbate R and Giusti B: Association of rs1466535 LRP1 but not rs3019885 SLC30A8 and rs6674171 TDRD10 gene polymorphisms with abdominal aortic aneurysm in Italian patients. J Vasc Surg 61: 787-792, 2015.

28. Ye Z, Austin E, Schaid DJ, Bailey KR, Pellikka PA and Kullo IJ: A DAB2IP genotype: Sex interaction is associated with abdominal aortic aneurysm expansion. J Investig Med 65: 1077-1082, 2017

29. Giusti B, Galora S, Saracini C, Pratesi G, Gensini GF, Pulli R, Pratesi C and Abbate R: Role of rs1466535 low density lipoprotein receptor-related protein 1 (LRP1) gene polymorphism in carotid artery disease. Atherosclerosis 237: 135-137, 2014.

30. Webb TR, Erdmann J, Stirrups KE, Stitziel NO, Masca NG, Jansen H, Kanoni S, Nelson CP, Ferrario PG, König IR, et al: Systematic evaluation of pleiotropy identifies 6 further loci associated with coronary artery disease. J Am Coll Cardiol 69: 823-836, 2017.

31. Kappert K, Böhm M, Schmieder R, Schumacher H, Teo K, Yusuf S, Sleight P and Unger T; ONTARGET/TRANSCEND Investigators: Impact of sex on cardiovascular outcome in patients at high cardiovascular risk: Analysis of the Telmisartan randomized assessment study in ACE-intolerant subjects with cardiovascular disease (TRANSCEND) and the ongoing telmisartan alone and in combination with ramipril global end point trial (ONTARGET). Circulation 126: 934-941, 2012.

32. Regitz-Zagrosek V, Oertelt-Prigione S, Seeland U and Hetzer R: Sex and gender differences in myocardial hypertrophy and heart failure. Circ J 74: 1265-1273, 2010.

33. Dudas K, Björck L, Jernberg T, Lappas G, Wallentin L and Rosengren A: Differences between acute myocardial infarction and unstable angina: A longitudinal cohort study reporting findings from the Register of Information and Knowledge about Swedish Heart Intensive Care Admissions (RIKS-HIA). BMJ Open 3: pii: e002155, 2013.

This work is licensed under a Creative Commons Attribution-NonCommercial-NoDerivatives 4.0 International (CC BY-NC-ND 4.0) License. 